\title{
IN VITRO ANTIMICROBIAL ACTIVITY OF ROOT EXTRACT OF CLITORIA TERNATEA
}

\author{
AMITA SHOBHA RA0 ${ }^{1 *}$, SHOBHA KL ${ }^{1}$, PRATHIBHA MD'ALMEIDA ${ }^{2}$, KIRANMAI S RAI ${ }^{2}$
}

${ }^{1}$ Department of Microbiology, Melaka Manipal Medical College, Manipal University, Manipal, Karnataka, India. ${ }^{2}$ Department of Physiology, Melaka Manipal Medical College, Manipal University, Manipal, Karnataka, India. Email: amitarao@rediffmail.com

Received: 15 May 2017, Revised and Accepted: 11 July 2017

ABSTRACT

Objective: Infections caused by Gram-negative bacteria are important causes of morbidity and mortality. Extracts of plants and herbs such as Clitorea ternatea are used as diuretic. This work attempts to find out antimicrobial activity of aqueous and alcoholic extract of $C$. ternatea roots against Pseudomonas aeruginosa (ATCC 27853), Escherichia coli (ATCC 25922), clinical strains of Klebsiella pneumoniae, and Candida albicans.

Methods: The agar well-diffusion method was done using Mueller Hinton agar and Sabouraud's dextrose agar. The microorganism grown in peptone water was inoculated into culture medium. $4 \mathrm{~mm}$ diameter well punched into the agar was filled with $20 \mu \mathrm{l}$ of aqueous and alcoholic root extracts C. ternatea extracts in various concentrations $(100-25 \mu \mathrm{g} / \mathrm{ml})$. The plates were incubated and antimicrobial activity was evaluated.

Results: Aqueous root extract of $C$. ternatea with the concentration of $100 \mu \mathrm{g} / \mathrm{ml}$ showed zone of inhibition against $E$. coli (ATCC 25922 ) $18 \mathrm{~mm}$, P. aeruginosa (ATCC 27853) $14 \mathrm{~mm}$, multidrug resistant strain of $K$. pneumoniae $15 \mathrm{~mm}$. Alcoholic extract of $C$. ternatea with the concentration of $100 \mu \mathrm{g} / \mathrm{ml}$ showed zone of inhibition of $35 \mathrm{~mm}$ against E. coli (ATCC 25922), P. aeruginosa (ATCC 27853) $22 \mathrm{~mm}$, and multidrug resistant strain of K. pneumoniae $28 \mathrm{~mm}$. C. albicanswas resistant to both extract of $C$. ternatea root.

Conclusions: Alcoholic extract of $C$. ternatea is a better antibacterial agent against multidrug resistant Klebsiella species and other Gram-negative pathogens. Further, studies are required to identify active substances from the alcoholic extracts of $C$. ternatea for treating infections.

Keywords: Clitorea ternatea, Antimicrobial sensitivity, Multidrug resistant.

(C) 2017 The Authors. Published by Innovare Academic Sciences Pvt Ltd. This is an open access article under the CC BY license (http://creativecommons. org/licenses/by/4. 0/) DOI: http://dx.doi.org/10.22159/ajpcr.2017.v10i11.19992

\section{INTRODUCTION}

Health-related quality of human life has been benefited since the introduction of antibiotics [1]. Medicinal plants and herbs are used for treatment of infections. Hence, their therapeutic potential, biological properties, and safety have to be useful to take decisions of their use [2,3]. History of India reveals the usage of medicinal plants to treat various diseases [4]. Lots of efforts are made to ascertain new antimicrobial compounds from plants. Antibacterial activities in medicinal plants have been reported $[5,6]$. In the need to develop superior drugs toward microbial infections, researchers are focusing their attention more toward herbal medicine [7]. Clitoria ternatea $L$. (butterfly pea in English) belongs to the family Fabaceae and subfamily Papilionaceae is an herbaceous perennial legume valued for its forage and medicinal importance. Extracts of $C$. ternatea has been used since time immemorial to treat mental disorders since it has property of being a good nervine tonic [8]. There are reports on callus induction and antimicrobial activity of seed and callus extracts of $C$. ternatea $\mathrm{L}$. $[9,10]$.

The objective of our study is to find out the antimicrobial activity of aqueous and alcoholic extract of $C$. ternatea roots against Gram-negative bacteria and fungi.

\section{METHODS}

\section{Plant collection}

C. ternatea roots collected from 2 to 3 years old plants, identified and confirmed as C. ternate by the Department of Pharmacognosy, College of Pharmaceutical Sciences, Manipal, were used for extraction.

\section{Aqueous root extraction}

Fresh roots of $C$. ternatea were collected, cleaned, cut into small pieces, and dried sunshade. It was then hand powdered. Dry powder was weighed and mixed with distilled water at 1:10 ratio and boiled over a low flame for half an hour, cooled, and decanted. Residue was mixed with distilled water (1:10) and boiled for 30 minutes, cooled, and decanted. The above procedure was repeated twice. The clear supernatant obtained each time was decanted and then centrifuged (3000 rpm for 5 minutes) and the supernatant was evaporated on low flame, to get a thick paste like extract, which was later dried in an incubator at $37^{\circ} \mathrm{C}$ and the dry powder so obtained was stored in a dessicator [11].

\section{Ethanol extract preparation}

The shade dried C. ternatea roots were grinded to powder. A known amount of powdered material was added to ethanol in the ratio of 1:16. Extract was prepared using Soxhlet apparatus. The extraction was done for 48 hrs duration. The crude extracts thus obtained were filtered using Whatmen filter paper No. 1 and the solvents were evaporated to dry using water bath at $40^{\circ} \mathrm{C}$. The dry extract was labeled and stored in the desiccator [12].

\section{Antimicrobial activity}

Gram-negative bacteria Pseudomonas aeruginosa (ATCC 27853), Escherichia coli (ATCC 25922), clinical isolate (multidrug resistant strain) of Klebsiella pneumoniae, and Candida albicanswas used.

The antibacterial and antifungal activity was determined using the agar well-diffusion method.

The above mentioned bacterial and fungal strains were revived by plating on nutrient agar and Sabouraud's dextrose agar (SDA), respectively. Isolated colonies were selected after overnight incubation at $37^{\circ} \mathrm{C}$. Identification of the organisms was done by standard procedure. Isolated bacterial colonies were then transferred to sterile MuellerHinton broth, and $C$. albicans was transferred to Sabouraud's dextrose broth and incubated overnight. 0.5 McFarland's turbidity standard 
was used to adjust the concentration of growth of microorganisms to $10^{5} \mathrm{CFU} / \mathrm{ml}$. Drugs used as positive control were ampicillin $10 \mu \mathrm{g}$ and ketaconazole $15 \mu \mathrm{g}$ [13].

\section{Determination of antibacterial activity}

Mueller-Hinton Agar (MHA) measuring $20 \mathrm{ml}$ each was poured into petri dishes. The bacterial culture was spread over the surface of the MHA plate. $4 \mathrm{~mm}$ diameter wells were punched into the agar and filled with $20 \mu \mathrm{l}$ solution of test compounds in various concentrations $(100$, 50,25 , and $12.5 \mu \mathrm{g} / \mathrm{ml}$ ). The inoculated plates were then kept in the incubator for $18 \mathrm{hrs}$ at $37^{\circ} \mathrm{C}$. Tests were done in triplicates and the average of the three was considered for the study.

\section{Determination of antifungal activity}

$20 \mathrm{ml}$ of SDA was poured into each petridishes. Culture of the C. albicans was spread over the surface of the SDA plate. Wells were punched into the agar plate measuring $4 \mathrm{~mm}$ in diameter and filled with $20 \mu \mathrm{l}$ solution of test compounds in various concentrations $(100,50,25$, and $12.5 \mu \mathrm{g} / \mathrm{ml})$. The plates were then kept in the incubator for $18 \mathrm{hrs}$ at $37^{\circ} \mathrm{C}$. Tests were done in triplicates and the average of the three was considered for the study.

\section{Statistical analysis}

Data are summarized as mean \pm standard deviation. All comparison between solvent and concentration was done using two way ANOVA and $\mathrm{p}<0.005$ was considered statistically significant.

\section{RESULTS}

The root of $C$. ternatea (aqueous extract) with the concentration of $100 \mu \mathrm{g} / \mathrm{ml}$ showed zone of inhibition against E. coli (ATCC 25922)
$18 \mathrm{~mm}$, P. aeruginosa (ATCC 27853) $14 \mathrm{~mm}$, and multidrug resistant strain of $K$. pneumoniae $15 \mathrm{~mm}$ (Table 1$)$.

Root of C. ternatea (alcoholic extract) with the concentration of $100 \mu \mathrm{g} / \mathrm{ml}$ showed zone of inhibition of $35 \mathrm{~mm}$ against E. coli (ATCC 25922), P. aeruginosa (ATCC 27853) $22 \mathrm{~mm}$, multidrug resistant strain of $K$. pneumoniae $28 \mathrm{~mm}$. C. albicans was resistant to both aqueous and alcoholic extract of $C$. ternatea root (Table 2).

There is a decrease in zone of inhibition with decrease in concentration which is statistically significant $(\mathrm{p}<0.001)$. Similarly, when we compare the zone of inhibition between the aqueous and alcoholic extracts there is statistically significant difference in the mean zone of inhibition $(\mathrm{p}<0.001)$ (Table 3)

Comparison of zone of inhibition between the aqueous and alcoholic extract for each concentration depicted a statistically significant difference in the means for the concentration of 100,50 , and $25 \mu \mathrm{g} / \mathrm{ml}$ (p<0.001) for E. coli (ATCC 25922), P. aeruginosa (ATCC 27853), and MDR $K$. pneumoniae and for the concentration of $12.5 \mu \mathrm{g} / \mathrm{ml}$ the aqueous extract was resistant to all the organism used in the test.

\section{DISCUSSION}

Medicinal plants are rich sources of antimicrobial agents which are used medicinally in different countries and are a source of many potent drugs used for traditional medicine. Medicinal plants exhibit antimicrobial activity by different mechanisms. This can be achieved by inhibition of cell wall synthesis, interference with the permeability of cell membrane, cause membrane disruption, modifying cellular constituents, and cell

Table 1: Zones of inhibition of aqueous extract of $C$. ternatea against various organisms

\begin{tabular}{|c|c|c|c|c|}
\hline \multirow[t]{2}{*}{ Organism } & \multicolumn{4}{|c|}{ Zone of inhibition (mm) } \\
\hline & Extract $100 \mu \mathrm{g} / \mathrm{ml}$ & Extract $50 \mu \mathrm{g} / \mathrm{ml}$ & Extract $25 \mu \mathrm{g} / \mathrm{ml}$ & Extract $12.5 \mu \mathrm{g} / \mathrm{ml}$ \\
\hline E. coli (ATCC 25922) & 18 & 13 & 10 & - \\
\hline P. aeruginosa (ATCC 25922) & 14 & 11 & 10 & - \\
\hline MDR K. pneumoniae & 15 & 10 & 8 & - \\
\hline C. albicans & - & - & - & - \\
\hline
\end{tabular}

C. ternatea: Clitorea ternatea, E. coli: Escherichia coli, K. pneumonia: Klebsiella pneumonia, C. albicans: Candida albicans, P. aeruginosa: Pseudomonas aeruginosa, MDR: Multidrug resistant

Table 2: Zones of inhibition of alcoholic extract of $C$. ternatea against various organisms

\begin{tabular}{|c|c|c|c|c|}
\hline \multirow[t]{2}{*}{ Organism } & \multicolumn{4}{|c|}{ Zone of inhibition (mm) } \\
\hline & Extract $100 \mu \mathrm{g} / \mathrm{ml}$ & Extract $50 \mu \mathrm{g} / \mathrm{ml}$ & Extract $25 \mu \mathrm{g} / \mathrm{ml}$ & Extract $12.5 \mu \mathrm{g} / \mathrm{ml}$ \\
\hline E. coli (ATCC 27853) & 35 & 30 & 22 & 10 \\
\hline P. aeruginosa (ATCC 25922) & 22 & 15 & 10 & 8 \\
\hline MDR K. pneumoniae & 28 & 17 & 9 & - \\
\hline C. albicans & - & - & - & - \\
\hline
\end{tabular}

C. ternatea: Clitorea ternatea, E. coli: Escherichia coli, K. pneumonia: Klebsiella pneumonia, C. albicans: Candida albicans, P. aeruginosa: Pseudomonas aeruginosa,

MDR: Multidrug resistant

Table 3: Descriptive statistics - Dependent variable

\begin{tabular}{|c|c|c|c|c|c|c|}
\hline \multirow[t]{3}{*}{ Concentration } & \multicolumn{6}{|l|}{ Mean \pm SD } \\
\hline & \multicolumn{2}{|c|}{ E. coli (ATCC 25922) } & \multicolumn{2}{|c|}{ P. aeruginosa (ATCC 27853) } & \multicolumn{2}{|c|}{ MDR K. pneumoniae } \\
\hline & **Aqueous & Alcoholic & **Aqueous & Alcoholic & ${ }^{* *}$ Aqueous & Alcoholic \\
\hline $100 \mu \mathrm{g} / \mathrm{ml}^{*}$ & 18.000 & 34.667 & 13.667 & 22.000 & 9.667 & 27.667 \\
\hline $50 \mu \mathrm{g} / \mathrm{ml}^{*}$ & 12.667 & 30.000 & 10.667 & 15.000 & 9.667 & 16.667 \\
\hline $25 \mu \mathrm{g} / \mathrm{ml}^{*}$ & 10.000 & 21.667 & 9.667 & 10.000 & 8.333 & 8.667 \\
\hline $12.5 \mu \mathrm{g} / \mathrm{ml}$ & - & 9.667 & - & 7.667 & - & - \\
\hline
\end{tabular}

${ }^{*} \mathrm{p}<0.001$ for comparison between the concentration 100,50 and $25 \mu \mathrm{g} / \mathrm{ml} ;{ }^{* *} \mathrm{p}<0.001$ for comparisons between the aqueous extract with the alcoholic

extract. SD: Standard deviation, C. ternatea: Clitorea ternatea, E. coli: Escherichia coli, K. pneumonia: Klebsiella pneumonia, C. albicans: Candida albicans,

P. aeruginosa: Pseudomonas aeruginosa, MDR: Multidrug resistant 
damage or cell mutation [14]. Most of the solvents such as ethanol, hexane, and methanol when used for plant extract showed inhibitory effect on Gram-positive and Gram-negative bacteria [15].

Haripriya et al. [16] observed that petroleum ether extracts of Selaginella involvens showed higher antibacterial activity against E. coli and Pseudomonas. Ponnusamy et al. [4] in their study showed ethyl acetate, ethanol, acetone, and petroleum ether extracts had maximum zone of activity against Aeromonas formicans, Aeromonas hydrophila, Bacillus subtilis, E. coli, K. pneumonia, P. aeruginosa, and Streptococcus agalactiae. In our present study of $C$. ternatea (ethanol extract) had better antibacterial activity than $C$. ternatea (aqueous extract) $\mathrm{p}<0.001$. The $C$. ternatea (ethanol extract) was also effective against multidrug resistant strains of $K$. pneumoniae. Our study was in concordance with the study conducted by Haripriya et al. [4] and Ponnusamy et al. [16].

\section{CONCLUSION}

Present study suggests that $C$. ternatea was effective against multidrug resistant microorganism, especially $K$. pneumoniae. There is a good scope for the development of natural drugs. Further, research is required in drug development program to identify the active compounds which is responsible for the plants biological activity.

\section{REFERENCES}

1. Bhalodia NR, Shukla VJ. Antibacterial and antifungal activities from leaf extracts of Cassia fistulal: An ethnomedicinal plant. J Adv Pharm Technol Res 2011;2(2):104-19.

2. Al-Snafi AE. Pharmacological importance of Clitoria ternatea. A review. IOSR J Pharm 2016;6(3):68-83

3. Al-Snafi AE. Chemical constituents and pharmacological importance of Agropyronrepens. A review. Res J Pharmacol Toxicol 2015;1(2):37-41.

4. Ponnusamy S, Gnanaraj WE, Marimuthu J, Selvakumar V, Nelson J.
The effect of leaves extracts of Clitoria ternatea Linn against the fish pathogens. Asian Pac J Trop Med 2010;3(9):723-6.

5. Dixit A, Singh H, Sharma RA, Sharma A. Estimation of antioxidant and antibacterial activity of crude extracts of Thevetia peruviana (pers.) K. Schum. Int J Pharm Pharm Sci 2015;7(2):55-9.

6. Bushra Beegum NR, Devi TG. Antibacterial activity of selected seaweeds from Kovalam south West coast of India. Asian J Microbiol Biotechnol Environ Exp Sci 2003;5(3):319-22.

7. Kamsala RV, Lepakshi BM, Padma Y, Venkata Raju RR. Studies on antimicrobial and antioxidant properties of leaf extracts of Syzygium alternifolium (wt.) walp. Int J Pharm Pharm Sci 2015;7(2):139-43.

8. Sivaranjan VV, Balachandran I. Ayuruedic Drugs and Their Plant Sources. New Delhi: Oxford \& IBM; 1994. p. 425-8.

9. Devi BP, Boominathan R, Mandal SC. Anti-inflammatory, analgesic and antipyretic properties of Clitoria ternatea root. Fitoterapia 2003;74(4):345-9.

10. Mhaskar AV, Prakash K, Vishwakarma KS, Maheshwari VL. Callus induction and antimicrobial activity of seed and callus extracts of Clitoria ternatea L. Curr Trends Biotechnol Pharm 2010;3(4):561-7.

11. Rai KS, Murthy KD, Karanth KS, Rao MS. Clitoria ternatea (Linn) root extract treatment during growth spurt period enhances learning and memory in rats. Indian J Physiol Pharmacol 2001;45(3):305-13.

12. Shakya VK, Saxena S, Shakya A. Effect of ethanolic extract of Allium sativum bulbs on streptozotocinet induced diabetic rats. J Chem Pharm Res 2010;2(6):171-5.

13. Rao AS, Nayanatara AK, Kaup SR, Sharma A, Kumar BA, Bhavesh D, et al. Potential antibacterial and antifungal activity of aqueous extract of Cynodon dactylon. Int J Pharm Sci Res 2011;2(11):2889-93.

14. Achika JI, Ndukwe GI, Ayo RG. Phytochemical screening and antimicrobial studies of aerial part of Aeschynomene uniflora Mey. Ind Chem 2016;2:113.

15. Rates SM. Plants as source of drugs. Toxicon 2001;39(5):603-13.

16. Haripriya D, Selvan N, Jeyakumar N, Periasamy R, Johnson M, Irudayaraj V. The effect of extracts of Selaginella involvens and Selaginella inaequalifolia leaves on poultry pathogens. Asian Pac J Trop Med 2010;3(9):723-6. 